\title{
Application of Genetic Algorithm in Design of water Tanks
}

\author{
Rajiv Gupta
}

\begin{abstract}
Design of water tanks is a specialized field, which requires experience and sound knowledge of engineering methodologies. Economy and Cost analysis of water tanks also become important especially in case of large capacity water tanks. This research paper presents an algorithm to optimize the tank design and the construction cost for a given volume of water tank using Genetic Algorithm (GA). Genetic Algorithm proves to be an efficient search algorithm to optimize design and cost of water tanks. Genetic Algorithm chooses a proper ratio of radius to height and the cost can be reduced by $20 \%$. Parametric study has also been carried out to study the effect of various GA parameters on the optimized cost of construction.
\end{abstract}

Keywords: Genetic Algorithm, Optimal design

\section{Introduction}

Storage tanks are indispensable structures to be constructed in every town or locality. It may be used to store water domestic supply, rainwater, chemicals, petrols, etc. Water tanks may be classified as overground, underground, over-head or Intze tanks [1]. It is a normal practice that either the tanks are overdesigned or wasteges are not considered in terms of choosing the dimensions of the tanks, which results in high cost which can be minimized. The paper considers the different alternatives in terms of height to radius ratio, satisfies also the structural needs and consider the materials which are available. This paper is based on special purpose computer programs, OPTITANK_UNDERGROUND and OPTITANK - OVERGROUND developed in C language to optimize the design of under-ground and over-ground tanks. The programs are based on Genetic Algorithm [2], a search algorithm inspired by process of natural evolution.
In the present study, genetic algorithm have been employed to obtain the optimum construction cost, tank dimension and other corresponding design parameters like grade of concrete, main reinforcement bar diameter, main reinforcement bar spacing for a given tank capacity [3]. The present work aims to aid design engineers by providing an approximate construction cost $[4,5]$ and other design parameters and to serve as an base for further works involving application of genetic and other similar evolutionary algorithms.

\section{Genetic Algorithm}

Genetic Algorithms are a family of computational models inspired by evolution .These algorithms encode a potential solution to a specific problem on a simple chromosome like data structure and apply recombination operators to these structures so as to preserve critical information. Genetic algorithms are often viewed as function optimizers although the range of problems to which genetic algorithms have been applied is quite broad.

\section{A. Genetic Algorithms Application for Structural Optimization}

Structural optimization involves sizing the components within constraints of structural adequacy to minimize the cost of structure. In our case of water tanks owing to various advantages cylindrical shape is preferred over rectangular tanks. Cylindrical tanks being axi-symmetric provide exact and easy analysis. Also since circular shape has minimum perimeter for a given area, the cost of shuttering and plastering can be reduced in case of cylindrical tanks. Using genetic algorithm, fitness value of chromosomes which is assigned as cost of structure, is evaluated corresponding to randomly generated tank dimension parameter the height of the tank to diameter ratio. For a particular shape of tank, Genetic algorithm searches 
Proc. of the Intl. Conf. on Advances in Civil, Structural and Mechanical Engineering - ACSM 2015. Copyright (C) Institute of Research Engineers and Doctors, USA .All rights reserved.

ISBN: 978-1-63248-039-2 doi: 10.15224/ 978-1-63248-039-2-18

the minimum possible cost for the fixed volume capacity of tank and the corresponding tank dimensions. Hence an optimized tank design is obtained.The flowchart for the computer program developed is as shown in Figure 1.

\section{Optimized Design of over-Ground Tank}

The OPTITANK_underground includes the tank design subroutine and genetic algorithm subroutine.The tank design subroutine takes a randomly generated value of height to diameter and performs structural analysis for the flexible base tank supported on slab resting on ground for a particular tank volume provided as input.The Tank design sub routine is followed by evaluation of cost. The total volume of steel and concrete is calculated after the designing of structure. Total cost for structure is calculated using the rates schedule available from PWD (Public works department), Government of India. Now as per the flowchart, the cost is assigned as the fitness value for each chromosome corresponding to a particular height to diameter ratio. Then genetic algorithm searches the entire search space to find the height to diameter ratio for which the cost is minimum. The corresponding grade of

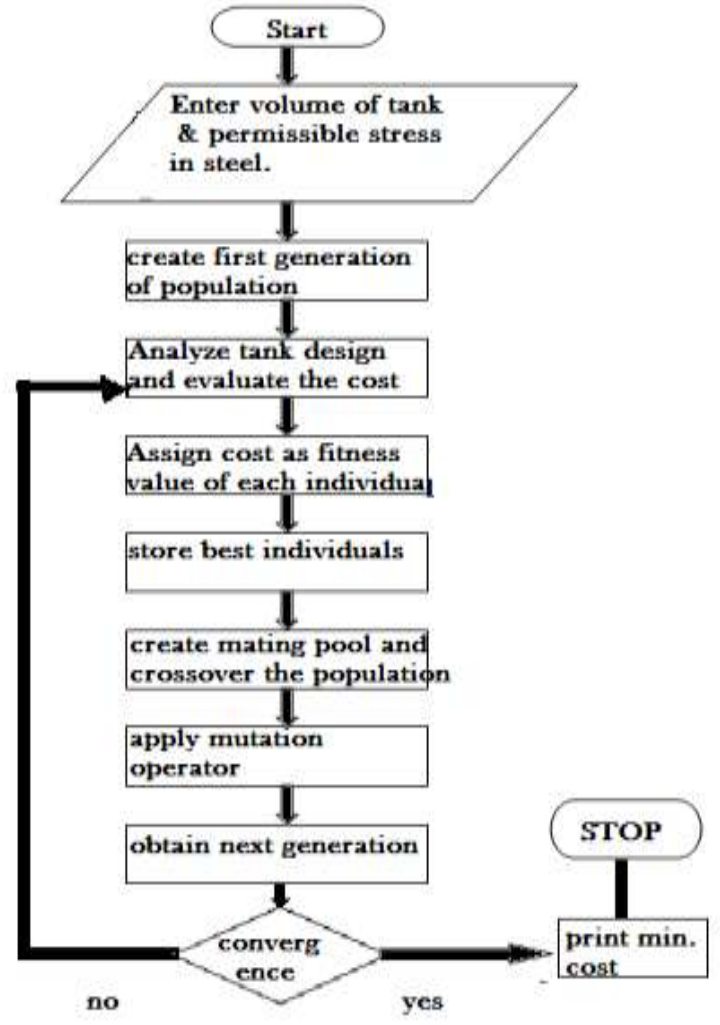

Figure 1: Program flowchart concrete for four discrete grades M20,M25, M30 and M35 and bar diameter from 16, 18, 20, 22, 25, 28, 30 and $32 \mathrm{~mm}$ are also generated as output.A sample output has been included in Appendix-I.

Using the computer code OPTITANK_overground entire database for large capacity water tanks can be generated as depicted in Table1.

\section{A. Checking the effectiveness of Genetic Algorithm search for overground tank design}

Genetic algorithm converges at a particular value of fitness, in our case the cost of water tank. A separate code GLOBAL_CHECK_Overground has been developed to check the deviation of Genetic Algorithm search result and absolute minimum using GLOBAL_CHECK._overground.The results show good convergence as indicated in Figure 2.

\section{Test case:}

Minimum cost for 500 cumecs cylindrical tank

Rs 288444 for Height/Diameter ratio: 0.347(using OPTI-OVER GROUND)

Rs 288431 for Height/Diameter ratio: 0.346(using GLOBAL_CHECK_overground)

TABLE 1: COST ESTIMATION DATABASE FOR CYLINDRICAL OVER-GROUND TANK.

\begin{tabular}{|c|c|c|c|c|c|}
\hline $\begin{array}{c}\text { capacity } \\
\text { in } \\
\text { cumecs }\end{array}$ & $\begin{array}{c}\text { cost in } \\
\text { INR }\end{array}$ & $\begin{array}{c}\mathrm{r}(\mathrm{H} / \mathrm{D} \\
\text { ratio })\end{array}$ & $\begin{array}{c}\text { Grade of } \\
\text { concrete } \\
(\mathrm{Mpa})\end{array}$ & $\begin{array}{c}\text { Bar } \\
\text { diameter } \\
(\mathrm{mm})\end{array}$ & $\begin{array}{c}\text { Bar } \\
\text { spacing } \\
(\mathrm{mm})\end{array}$ \\
\hline 100 & 57810 & 0.05 & 20 & 16 & 280 \\
\hline 150 & 86658 & 0.628 & 30 & 20 & 250 \\
\hline 200 & 115494 & 0.546 & 30 & 22 & 270 \\
\hline 250 & 144331 & 0.488 & 30 & 22 & 240 \\
\hline 300 & 173156 & 0.445 & 30 & 25 & 280 \\
\hline 350 & 201984 & 0.414 & 30 & 25 & 260 \\
\hline 350 & 201984 & 0.414 & 30 & 25 & 240 \\
\hline 400 & 230811 & 0.386 & 30 & 25 & 250 \\
\hline 400 & 230811 & 0.386 & 30 & 25 & 260 \\
\hline 450 & 259627 & 0.363 & 30 & 28 & 260 \\
\hline 500 & 288444 & 0.347 & 30 & 28 & 240 \\
\hline 550 & 317269 & 0.332 & 30 & 28 & 290 \\
\hline 600 & 346079 & 0.316 & 30 & 30 & 270 \\
\hline 650 & 374893 & 0.304 & 30 & 30 & 260 \\
\hline 700 & 403715 & 0.292 & 30 & 30 & 290 \\
\hline 750 & 432526 & 0.281 & 30 & 32 & 270 \\
\hline 800 & 461334 & 0.270 & 30 & 32 & 260 \\
\hline 850 & 490144 & 0.265 & 30 & 32 & 290 \\
\hline 900 & 518954 & 0.257 & 30 & 32 & 280 \\
\hline 950 & 547775 & 0.25 & 30 & 32 & 270 \\
\hline 1000 & 576598 & 0.242 & 30 & 32 & 270 \\
\hline
\end{tabular}


Proc. of the Intl. Conf. on Advances in Civil, Structural and Mechanical Engineering - ACSM 2015.

Copyright (C) Institute of Research Engineers and Doctors, USA .All rights reserved.

ISBN: 978-1-63248-039-2 doi: 10.15224/ 978-1-63248-039-2-18

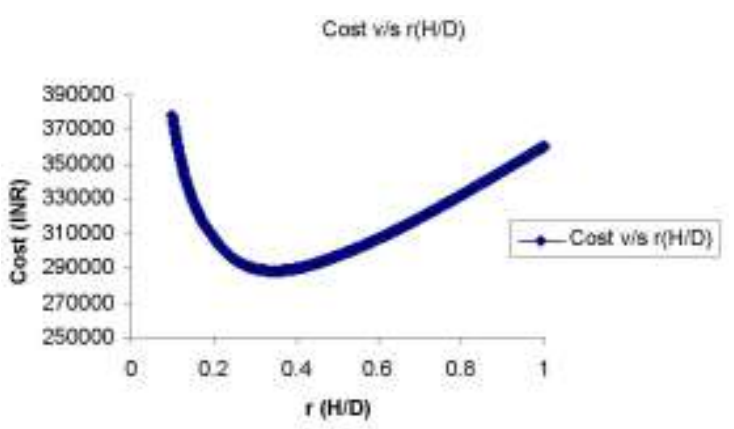

Figure 2: Variation of cost of construction with Height to diameter ratio of over-ground tank of capacity 500 cumecs.

\section{B. Optimized design of Under- ground tank}

The optimized design of underground tank follows similar flowchart as the over ground tank design. The underground tank structure consists of a cylindrical walled tank supported over a base slab and covered by a dome shaped roof.The input taken from the user are tank volume, permissible stress in steel and the net bearing capacity of the soil. The cost evaluated corresponding to a particular value of height to diameter ratio is assigned as the fitness value and the genetic algorithm searches the entire search space to find the height to diameter ratio corresponding to which the Cost is minimum.

TABLE 2: OPTIMIZED TANK DESIGN DATABASE FOR UNDER-GROUND TANKS.

\begin{tabular}{|c|c|c|c|c|c|}
\hline $\begin{array}{c}\text { Volume } \\
\text { of tank } \\
\text { (cumecs) }\end{array}$ & $\begin{array}{c}\text { Cost } \\
\text { (INR) }\end{array}$ & $\begin{array}{c}\text { r value } \\
(\mathrm{H} / \mathrm{D} \\
\text { ratio })\end{array}$ & $\begin{array}{c}\text { Bar } \\
\text { Diameter } \\
(\mathrm{mm})\end{array}$ & $\begin{array}{c}\text { Bar } \\
\text { spac- } \\
\text { ing } \\
(\mathrm{mm})\end{array}$ & $\begin{array}{c}\text { Grade } \\
\text { of } \\
\text { Concrete }\end{array}$ \\
\hline 100 & 142720 & 0.69 & 16 & 285 & M20 \\
\hline 150 & 211520 & 0.375 & 16 & 300 & M20 \\
\hline 200 & 281072 & 0.351 & 16 & 300 & M20 \\
\hline 250 & 350981 & 0.289 & 16 & 300 & M20 \\
\hline 300 & 422259 & 0.246 & 16 & 285 & M20 \\
\hline 350 & 496018 & 0.207 & 16 & 270 & M20 \\
\hline 400 & 567876 & 0.23 & 18 & 300 & M20 \\
\hline 450 & 642631 & 0.199 & 18 & 280 & M20 \\
\hline 500 & 721226 & 0.187 & 18 & 280 & M20 \\
\hline 550 & 791603 & 0.195 & 20 & 300 & M20 \\
\hline 600 & 866401 & 0.183 & 20 & 295 & M20 \\
\hline 650 & 941086 & 0.175 & 20 & 290 & M20 \\
\hline 700 & 1018238 & 0.164 & 20 & 290 & M20 \\
\hline 750 & 1097333 & 0.167 & 20 & 300 & M20 \\
\hline 800 & 1174352 & 0.16 & 22 & 295 & M20 \\
\hline 850 & 1250196 & 0.156 & 22 & 300 & M20 \\
\hline 900 & 1327131 & 0.152 & 22 & 300 & M20 \\
\hline 950 & 1408124 & 0.144 & 22 & 290 & M20 \\
\hline 1000 & 1487015 & 0.14 & 22 & 290 & M20 \\
\hline
\end{tabular}

A sample output for OPTITANK_underground has been included in appendix $\mathbf{I}$.

Using the computer code OPTITANK underground entire database for large capacity water tanks can be generated as depicted in Table 2.

\section{Checking the effectiveness of Genetic Algorithm for Under- ground tank design}

Similar to the check for over ground tank design a global check code, GLOBAL_CHECK_underground has been developed to check the effectiveness of genetic algorithm search. The results are shown in Figure 3.

Test case:

Minimum cost for 500 cumecs cylindrical tank Rs 721226 for Height/Diameter ratio: 0.187(using OPTI-OVER GROUND)

Rs 715825 for Height/Diameter ratio: 0.188 (using GLOBAL_CHECK_underground)

\section{Study of variations of $G A$ parameters on convergence of GA search}

A parametric study has been carried out to study the effect of various Genetic Algorithm parameters like cross-over probability, mutation probability and size of population. The effect of varying the crossover probability has been studied for 50, 60 and 70 percent cross over probability. The following conclusions can be made based on the curve in Figure 4:

i) Rate of convergence increases in case of cross over probability of 60 and $70 \%$ as compared to in the case of cross over probability of $50 \%$.

\section{Cost in INR V/s H/D ratio}

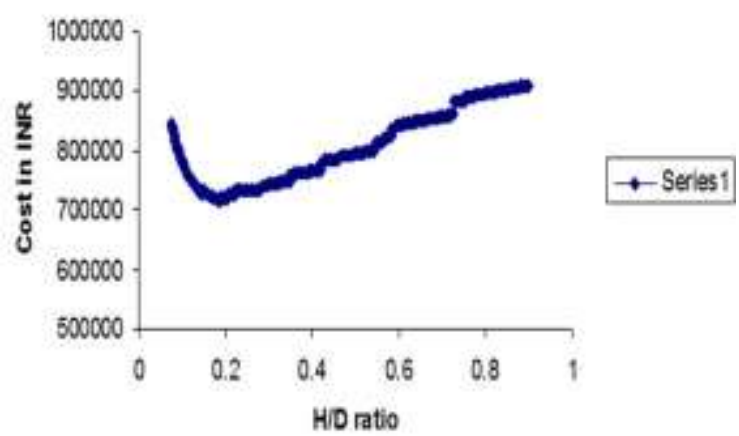

Figure 3: Cost of tank v/s height to diameter ratio for 500 cumecs under-ground tank. 
Proc. of the Intl. Conf. on Advances in Civil, Structural and Mechanical Engineering - ACSM 2015.

Copyright (C) Institute of Research Engineers and Doctors, USA .All rights reserved.

ISBN: 978-1-63248-039-2 doi: 10.15224/ 978-1-63248-039-2-18

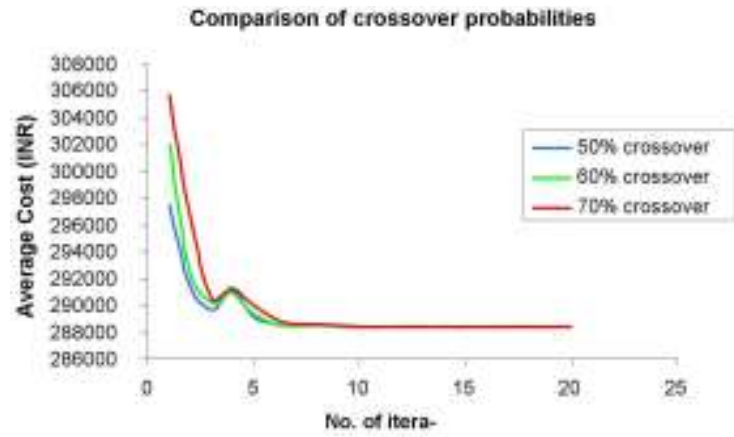

Figure 4: Comparison of Cross over probability for the test case of 500 cumecs overground tank.

ii) The curve shows a small peak in the average cost as number of iteration increases. This reflects the inclusion of certain chromosomes with lower fitness which are gradually eliminated owing to crossing over and mutation.

The variation of mutation probability from two to four percent shows no change in the rate of convergence or the converging value.

To check the effect of population variation on convergence rate and genetic Algorithm search value, four different cases values of population 26, 50, 76 and 100 are considered. The following conclusions can be drawn based on Figure 5:

i) For a small population like 26 Genetic algorithm search converges very fast towards a value which is much different from actual absolute minimum cost in search space

ii) As the population size increase Genetic Algorithm search converges towards the actual absolute minimum cost in search space

iii) The rate of convergence decreases from 26 population size to 100 .

Comparison of covergence rate for different populations

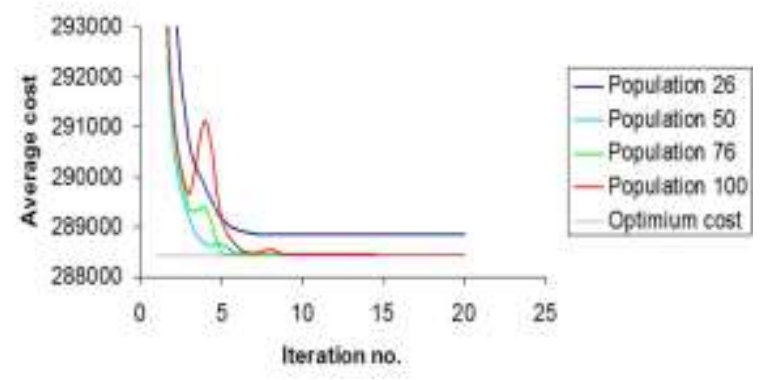

Figure 5: Comparison of convergence rate for different population.

\section{CONCLUSION}

In the present work, special purpose computer programs were developed to optimize water tanks' construction cost along with other design parameters.The work also demonstrates the effectiveness of Genetic Algorithm in aiding the design engineers in designing of water tanks. The results obtained using Genetic algorithm shows close convergence with the actual global minimum values. By choosing a proper ratio of radius to height, the cost can be reduced by $20 \%$ and genetic algorithm is the method in choosing a proper ratio.

\section{References}

[1] Punmia, B.C., and Jain A.K.. Reinforced Concrete Structure Laxmi Publication, Vol II, New Delhi, 2005.

[2] L, C.ee, and Ahn, J., Flexural Design of Reinforced Concrete Frames by Genetic Algorithm. Journal of Structural Engineering, ASCE, Vol. 129, No. 6, June 2003, pp. 762-774.

[3] IS 456. Plain and reinforced concrete, Bureau of Indian Standards, New Delhi, 2000.

[4] Pathak, K.K. and Agarwal, R., Cost Prediction of Overhead Water Tanks using Artificial Neural Networks, Journal of the Institution of Engineer, Civil engineering Division, India, 2003, vol. 84, Nov, pp. 153-158.

[5] Schedule of Rates: PWD Mizoram website, http://mizopwd.nic.in.

\section{APPENDIX - I}

\section{OPTITANK_overground}

Program Input:

Enter the tank volume in cubic metres:500

Enter the permissible stress in steel $\mathrm{N} / \mathrm{mm}^{2}: 115$

Enter the no. of iteration: 20

Program output:

************Final Result***********

*************Optimized tank design $* * * * * * * * * * *$

Tank Volume: 500 cumecs

Predicted Cost: Rs.288444

Grade of Concrete:

Bar Diameter: $28 \mathrm{~mm}$

Bar Spacing: $270 \mathrm{~mm}$

\section{OPTITANK_underground}

Program Input:

Enter the tank volume in cubic metres:500

Enter the permissible stress in steel N/mm $2: 115$

Enter the net bearing capacity of soil in $\mathrm{kg} / \mathrm{cm}^{2}=30$

Enter the no. of iteration:20 
Proc. of the Intl. Conf. on Advances in Civil, Structural and Mechanical Engineering - ACSM 2015.

Copyright (C) Institute of Research Engineers and Doctors, USA .All rights reserved.

ISBN: 978-1-63248-039-2 doi: 10.15224/ 978-1-63248-039-2-18

Program output:

************Final Result**********

$* * * * * * * * * * *$ Optimized tank design $* * * * * * * * * * *$

Tank Volume: 500 cumecs

Predicted Cost: Rs.716104

Grade of Concrete: M20

Bar Diameter: $18 \mathrm{~mm}$

Bar Spacing :280 mm

Net bearing capacity of the soil is sufficient!

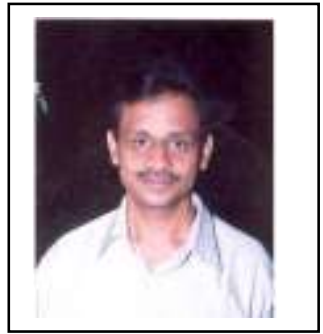

Senior Professor

Birla Institute of Technology and Science, Pilani

(Raj.) India 